\title{
How moving home influences appliance ownership: a Passivhaus case study
}

\author{
Chris Foulds • Jane Powell • Gill Seyfang
}

Received: 11 July 2014 / Accepted: 2 June 2015 / Published online: 10 July 2015

(C) The Author(s) 2015. This article is published with open access at Springerlink.com

\begin{abstract}
Low carbon dwellings shift the focus to electricity consumption and appliances by significantly lowering space heating energy consumption. Using a UK Passivhaus (low carbon) case study, interviews and pre/ post-move-in appliance audits were employed to investigate how moving home can change the appliance requirements of appliance-using practices. Changes in appliance ownership were due to differences in how appliance-using practices (e.g. cooking, laundering, homemaking) were being performed. Existing/new appliances complemented/conflicted with a new home on the basis of whether the social meanings of specific appliance-using practices (e.g. stylishness, convenience, thermal comfort, cleanliness) could be met. This was evident, when moving home more generally, by households buying new modern appliances and managing spatial constraints. More specifically, regarding Passivhaus, hosting and homemaking practices were performed in ways that met thermal comfort expectations, in addition to appliance purchasing also being influenced by a fear that the Passivhaus technologies could fail. Whilst skills and competences were needed to perform appliance-using practices, these were less prominent in influencing appliance ownership changes.
\end{abstract}

C. Foulds $(\bowtie)$

Global Sustainability Institute, Anglia Ruskin University, East Road, Cambridge CB1 1PT, UK

e-mail: chris.foulds@anglia.ac.uk

J. Powell · G. Seyfang

School of Environmental Sciences, University of East Anglia, Norwich NR4 7TJ, UK
Conclusions include reflections on how the elements of appliance-using practices change when moving home, as well as what adhering to building standards could mean for the standardisation of appliance-using practices and domestic life more generally.

Keywords Electrical devices $\cdot$ Purchasing $\cdot$ Social practice theory - Domestic energy consumption · Low energy homes $\cdot$ Passivhaus

\section{Introduction}

Appliance ownership has been consistently increasing year on year, with the total number of UK domestic electrical appliances having grown by $27 \%$ over 1996-2011 and this trends shows little sign of relenting (DECC 2013). The appliances included in the scope of the DECC ownership survey are mainly the traditionally high electricity-consuming white goods, with all home computing and consumer electronics (e.g. television, laptops, games consoles) and many cooking (e.g. microwave, kettle) appliances excluded, despite calls to give these more attention (e.g. Owen 2007). In this research paper, we take appliances to be electricityconsuming devices and only exclude lighting devices which play a largely unique role in everyday life.

In light of climate change concerns, there is a pressing need to reduce domestic energy consumption which in 2012 accounted for $29 \%$ of final energy usage (DECC 2013). Appliance usage, excluding lighting, is responsible for $18 \%$ of the carbon emissions attributed 
to UK households (calculated using UK DECC (2013) and Energy Saving Trust (2011) figures). UK domestic energy policy focuses more on improving dwelling fabric and thermal efficiency (e.g. 2016 zero carbon homes definition does not account for appliances (McLeod et al. 2012)); therefore, the proportion of appliances-related consumption will only increase as space heating demands lessen, and that is before even accounting for rises in appliance ownership. The emphasis should not be put on the house, but instead the home, so that research and policy considers how we live our everyday lives within the walls of our houses. How we go about making a house a home (perhaps across different technological contexts) needs further research since it shapes which appliances we choose to surround ourselves with.

Most appliances research has focused on identifying various external economic (e.g. cost, information, technology) and/or psychological (e.g. attitudes, values) factors, which affect an individual's decision-making regarding appliance ownership and use (e.g. Efstathiou et al. 2004; Leahy and Lyons 2010; Mansouri et al. 1996; O’Doherty et al. 2008; Zimmermann et al. 2012). Direct cause-effect relationships are thus typically sought. However, if we want to understand why new appliances are purchased and used as part of everyday life, these cause-effect viewpoints are too simplistic. Its linearity usually fails to capture the social influences that underpin practices (e.g. cooking, hosting, washing) which have been shown to often produce a markedly nonlinearity from intervention to outcome(s). Critiques have hence advocated focusing on the organisation and performance of practices (e.g. Gram-Hanssen 2010, 2013; Hargreaves 2011; Shove et al. 2012; Shove 2010). Switching the focus from individuals to the actual doings and sayings (practices) of everyday life is vital because these practices push/pull individuals in certain directions (e.g. regarding appliance disposal and purchasing).

In addition to furthering the empirical application of theories of social practice in domestic appliances research, other knowledge gaps also exist. Whilst it is hugely important that detailed discussion is given to key appliances separately, so as to be able to appreciate the historic role of specific appliances in trajectories of social practices, few studies have broadened out the scope to include all appliances (e.g. freezer focus: Hand and Shove 2007; Shove and Southerton 2000) or the whole dwelling (e.g. kitchen focus: Hand and Shove
2004; Shove and Hand 2000; Southerton 2001). It is the wider technological configuration (i.e. how appliances relate to one another as well as the dwelling) that in part provides opportunities for performing practices. There has been little research into how significant changes to the wider technological configuration - such as moving home - change the appliances-related requirements of practices. Wilhite (2012, p. 96) stated that moving home often stimulates 'the purchase of new appliances and changes in practices in the new home'. We argue that, in this quotation, 'and' should actually be 'due to' because practices drive our appliance demands. More research is needed to understand how moving home and different technological contexts can influence appliance-using practices and so shape appliance ownership. It would be particularly interesting to explore changes associated with moving into a low carbon dwelling because it would provide insight into how the next generation of (unfamiliar) building technologies could shape our everyday lives.

This paper aims to investigate how appliance-using practices, and thereby appliance ownership levels, may change after moving home. This will be achieved through the following three objectives:

1. Provide illustrative examples of how technologies - be they at the level of the building structure, or smaller-scale products that households bring with them into the home - can complement and conflict with appliances, showing how that can shape appliance ownership;

2. Consider building-level technologies associated with the Passivhaus (building energy efficiency) standard and discuss how that influences appliance ownership. Specifically focus on the heating role that appliances acquire in Passivhaus settings;

3. Broaden the focus by identifying and exploring key issues associated with how moving homes can more generally influence appliance ownership.

These involve investigating how appliance-using practices are performed and how they can change as a result of moving home, encountering different technologies, and inter-appliance relationships. The wider technological configuration is given explicit consideration, with attention given to what appliances households choose (consciously or not) to own as they appropriate a new material environment. This paper does not serve to provide an exhaustive list of all potential influences, 
instead detailing salient influences and everyday examples found in one UK affordable housing case study.

The case study is a small to medium-sized Passivhaus development, which provides energy efficiency through airtightness, super insulation, and Mechanical Ventilation with Heat Recovery (MVHR), in addition to a low carbon energy source through solar thermal technology. Homes built to this German design standard involve a set (or 'configuration') of technologies that are very different to traditionally constructed homes (which tend to have higher air leakage rates), and thus will serve as a useful comparison, as part of exploring whether households use different appliances across different technological contexts.

We begin by introducing theories of practice and summarising what it can offer analyses such as this ('Theoretical context'). More detail is then provided on the case study employed, its observed changes in appliance ownership at move-in, and then the methods adopted to explore the influences that underlie such changes ('Methodology'). The core of the paper is structured around presenting ('Findings') and discussing ('Discussion') findings associated with the three objectives. Conclusions are then presented on the practice-related changes that occur at move-in ('Conclusions').

\section{Theoretical context}

Theories of social practice draw on literature that has pulled away from the traditionally dominant individualistic approaches. These individualistic theories, be they rooted in more rational economics or the psychological perspective, typically model a number of factors (or contextual cues) which cause individuals to behave in certain ways. Individuals are therefore the primary change agent, as they respond to various contexts. This usually creates a theoretical linearity because individual behaviours are products of rigid cause-effect relationships. For example, the Habit-Discontinuity hypothesis (Verplanken et al. 2008) posits that there are key 'moments of change' (Thompson et al. 2011, p. 1) - such as moving home - when behaviour is more deliberately considered, making us more prone to other behavioural changes (e.g. living with different appliances). Such theoretical perspectives miss out on broader social dynamics and the often unanticipated consequences of major life changes, which can be captured by using practices as the central unit of analysis, as opposed to individuals. For instance, moving home, to name a few influences, could involve the following: new technological surroundings, exposure to different institutions, aspirations of how to occupy that home according to societal expectations, and this all interpreted through a lens based on past experience. These influences interact, sometimes unpredictably, in establishing new performances of everyday practices. Therefore, in many ways, moving home is actually a 'moment of change' - indeed this is fundamental to this paper - but the difference is that we regard moving as an intervention in practice and not as a change in contextual factors that individuals linearly respond to.

A practice is a 'routinized type of behaviour' (Reckwitz 2002, p. 249) which are the constituents of everyday life. Practices thus range from flying, driving and playing football to hosting guests, homemaking, cooking and showering. A 'practical rationality' (Sandberg and Haridimos 2011) exists in that individuals and households make decisions, consciously or not, in accordance with the practices they undertake. Practices-related research demands examination of broader social processes, which do not simply treat practices as additional contextual variables which individuals are subjected to. The onus needs to be on practices and how they are performed (by individuals and households being 'practitioners'), instead of individual energy consumers or appliance users. As McMeekin and Southerton reflect:

Conceptualising consumption in this way moves analytic attention away from specific goods and services and from individual expressions of preferences, towards an understanding of how products are appropriated as a consequence of the ways in which practices are socially ordered. In making such a conceptual shift, notions of demand, need and want are re-cast as the consequence of the 'doings' (or practices) through which daily lives consist: as Warde (2005, p. 137) puts it, 'activity generates wants, rather than vice versa'.

(McMeekin and Southerton 2012, p. 350)

This shifts the attention away from individual preferences and/or specific appliances in themselves, to appliance-using practices which over time create and maintain the need for specific appliances (e.g. laundering: washing machine, tumble dryer; cooking: oven, 
hobs, microwave). Such practices amass certain requirements as they are performed, be they technological or not, which in turn sustain further performances.

What these social practices require and how they are influenced has provided much debate amongst prominent social practice theorists. Indeed, the key theorists (who we now refer to) differ with regard to how they conceptualise practice. The foundations of the practices literature can, in part, be found in the work of Bourdieu (1984) and Giddens (1984) who interestingly barely mention technologies, instead opting for almost wholly 'social' theories. However in recent years, there has been an increasing acknowledgment that 'practices are intrinsically connected to and interwoven with objects' (Schatzki 2002, p. 106), which demonstrates a material turn within a wider 'practice turn' (Schatzki et al. 2001) in contemporary social theory. However, despite this commonly shared turn, differences in how exactly technologies are conceptualised as part of practices still remain. For example, whilst Schatzki notes materiality as being important, he still contends it as being something outside of a practice, and is hence why he talks of 'material arrangements' (Schatzki 2011, p. 4) being something distinct that bundles together with practices in the construction of social life. In addition, Warde (2005) positions materiality - and thus, for instance, the consumption of appliances - as being guided by practice and not as an element of practice. However, instead many have increasingly positioned materiality as a core influence (or element) of practice. This includes the work of Shove (in Shove et al. 2012: 'material'), Gram-Hanssen (2010a: 'technologies and material structure') and Reckwitz (2002: 'things'). As such, theories of practice literature now largely regard materiality as a key element of practice (Røpke 2009).

Materiality is 'constantly evolving and interrelated within itself. It is not one manageable coherent entity that can be targeted independently and manipulated at will so as to push or pull practices in desired directions. For instance, domestic appliances would offer nothing without the wider infrastructure of power stations and transmission lines that enable it. Appliance ownership and usage also depend on other technologies situated within the home, such as plug sockets or other appliances that already provide opportunities for practices. Appliances thus form part of a wider technological configuration.

Whilst technological configurations are the predominant focus of this paper, and has thus received the most introduction, it is only one of the elements shaping practices. Indeed, all the aforementioned theorists who tout technology as a key influence all agree that practices are constructed and organised in very complex ways. Practices are not only dependent on technologies relating to one another but also how that technological configuration relates to the configuration of the other practice elements across a range of different practices. For example, Shove et al. (2012) proposes the three elements of materials (products, objects), meanings (images, social expectations) and competences (skills, practical know-how). These elements emphasise the complexity of practices and that studies of technology-in-practice should investigate how technologies relate to various modes of competences (be it expert or tacitly derived) and meanings, as well as its surrounding material structure. Understanding the nuances of practice organisation is important here because households only own appliances because of the practices that utilise them.

The literature emphasises that practices, and by extension the appliances that assist them, depend on messy relationships (e.g. between practices; between the elements). Through a practices perspective, we investigate some of the underlying influences that underpin these messy relationships and thereby shape appliance ownership. This paper empirically furthers discussions on how appliances shape and in turn are shaped by domestic everyday practices.

\section{Methodology}

Case study description

A small to medium-sized UK Passivhaus affordable housing development was adopted as a case study. Passivhaus is a German energy efficiency building standard, which aims to achieve significant energy consumption savings through its super insulation and relative airtightness that lowers heat loss rates (Feist et al. 2005). Airtightness levels require the installation of MVHR systems for air quality purposes. Solar thermal and gas-fired boiler systems provide space heating through the MVHR (no radiators) and water heating. The very low heat loss rates mean that these systems provide very little space heating in actuality because heat is passively obtained through everyday life (e.g. appliance usage) and solar gain. As such, part of 
becoming Passivhaus-certified usually involves providing energy-efficient appliances, so as to mitigate overheating risks. However for the development studied, as with most UK social housing projects, no appliances were provided because that would have required maintenance responsibilities. The consequence was that the residents controlled which of their own appliances they used in their new Passivhaus homes.

The households' previous dwellings had been, contrastingly, more typical of the wide ranging UK housing stock. Housing types included semidetached, detached, mid-terrace, end-terrace and flats. Housing age was similarly diverse, ranging from construction in the late 1800 s to 2008. All dwellings had a central heating system with radiators, but the constituent boilers had different fuel supplies (e.g. gas, oil, wood, coal).

Around $29 \%$ of the new Passivhaus homes were shared ownership (i.e. part housing association and part householder owned), with the remaining $71 \%$ social tenants. The new occupants of the shared ownership homes were moving largely as part of making their first property investment. The social tenants were moving because of various different circumstances, including their previous socially rented dwelling was too small/large; they had lost their job and/or home; were keen to move away from their parents; wanted to live in a rural location; or were unhappy in their previous home (e.g. due to damp or safety concerns).

This Passivhaus development can provide unique insights because, as far as we are aware, no research has yet explored appliance ownership changes in the Passivhaus context. In addition, Passivhaus homes represent an interesting (low energy) case that was sufficiently different to the rest of the housing stock. As such, the case study can provide insights on what appliance ownerships changes may occur in response to energy efficiency improvements to the housing stock more generally. But, beyond this, a detailed investigation of the influences underpinning appliance ownership changes around move-in also brings influences to the fore that relate almost solely to the processes of moving and then making a new home. In addition, as we now go on to make clear, our methods rest on collecting data before and after move-in (which is rarely possible), and thus we are uniquely placed to explore these processes further.
Outlining the research problem: what were the changes in appliance ownership around move-in?

Energy consumption data were gathered to examine whether energy usage had changed by moving home. Pre-move-in energy data were collected through past bills (proportionally scaled up/down to find annual estimates), whereas manual gas and electricity meter readings (taken a year apart) were used for the post-move-in comparisons. Floor plan information enabled energy consumption to be normalised on a per square metre basis. Each household's energy use was summed under either electricity or heating fuel (e.g. coal, wood, oil, gas); this distinction was aided by the fact that no dwellings were electrically heated. These data provide a useful context for understanding the broader energy demand-related consequences of potential changes in appliance ownership.

There was a marked reduction in space and water heating fuel consumption when moving from conventional to Passivhaus dwellings (Fig. 1). The mean annual heating fuel consumption dropped by over $85 \%$, from $219 \mathrm{kWh} /\left(\mathrm{m}^{2}\right.$ a) (min-max, $141-284 \mathrm{kWh} /\left(\mathrm{m}^{2}\right.$ a) ) to $32 \mathrm{kWh} /\left(\mathrm{m}^{2}\right.$ a) (min-max, $20-61 \mathrm{kWh} /\left(\mathrm{m}^{2} \mathrm{a}\right)$ ). These findings reflect a wider trend in thermal efficiency improvements which, whilst lowering heating fuel usage, increases electricity's proportion of total energy usage and thereby redirects attention from heating fuel to electricity demand (Monahan and Powell 2011).

Many dwelling-level technologies (e.g. solar thermal, boiler, airtightness, insulation) directly shape how much heating fuel is used, and thus also the practices that require these fuels. In contrast, practices that consume electricity generally use smaller-scale technologies that the households bring with them (e.g. appliances), as part of how they occupy and appropriate their new homes. On the surface, this may seem to fit well with Fig. 1 since it reveals how electricity consumption in their previous conventional dwelling (mean, $47 \mathrm{kWh} /$ $\left(\mathrm{m}^{2} \mathrm{a}\right)$; min-max, 22-67 $\left.\mathrm{kWh} /\left(\mathrm{m}^{2} \mathrm{a}\right)\right)$ and new Passivhaus dwelling (mean, $45 \mathrm{kWh} /\left(\mathrm{m}^{2} \mathrm{a}\right)$; min-max, $\left.25-64 \mathrm{kWh} /\left(\mathrm{m}^{2} \mathrm{a}\right)\right)$ are very similar. One could therefore infer that similar electricity consumption is a consequence of households using the same electrical appliances.

However, the two appliance audits that were undertaken for each household suggest clear changes in household appliance ownership around move-in. The first audit was conducted around 2 months before 
Fig. 1 Comparing actual energy consumption: conventional versus Passivhaus homes

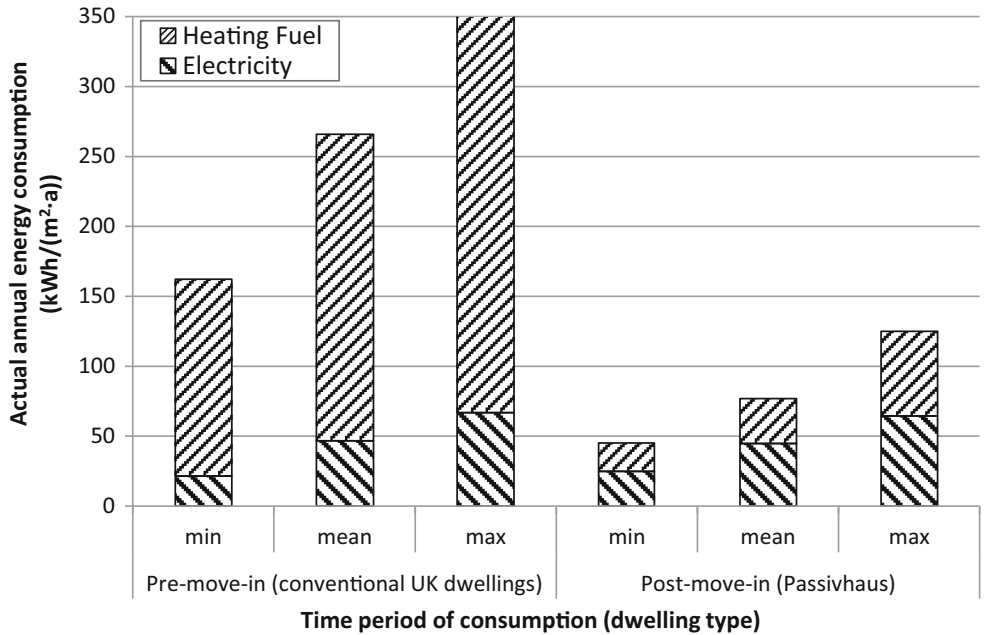

move-in (April-May 2011) and the second was around 16 months after move-in (October-November 2012). The audits involved recording the existence of every appliance, the specification of larger appliances (e.g. white goods), the approximate purchase date of each appliance and whether it was second-hand. Ownership included appliances that were regularly used, but not owned, by the household (e.g. loans) as well as those that were owned by household members.

The audits revealed that the total number of appliances owned by households dropped by $5 \%$ to a mean average of 25 (min-max, 13-34) appliances post-movein. A separate study of 251 English households showed average ownership to be 41 (min-max, 13-85) appliances (Owen 2012), thereby suggesting that the practices of this study's households use relatively fewer appliances. However, we argue that such averages cannot convey the full story because practices give technologies very different meanings with, for instance, owning and using a kettle constituting something very different to owning and using a washing machine. An issue for further investigation in this study is thus if (and perhaps how) the meanings attached to different appliances may change around move-in, in addition to what that meant for appliance ownership.

In relation to this, it is important to note that no household kept all the same appliances between preand post-move-in. While ownership changes ranged considerably, from a decrease of $33 \%$ to an increase of $47 \%$, there were many similarities across the sampled households (see Table 1 for specific details). For example, almost $80 \%$ of cookers were replaced, in addition to both $50 \%$ of washing machines and cold appliances with freezer capabilities. More broadly, around $39 \%$ of the larger (and more electricity consuming) appliances were replaced. Much of this study will implicitly consider the influences that underlie all these changes.

In purchasing replacements, considerably more of the larger appliances were bought new, which would have consequently improved the energy efficiency of the respective appliances. Indeed there were very few households that purchased second-hand replacements. In addition, the majority of the replacements occurred in the weeks surrounding move-in itself. In fact if we were to discount this round of move-in replacements, major appliances (as per Table 1) were on average last purchased 4 years and 5 months before move-in. It is therefore clear that moving into these new homes coincided with ownership changes to a fairly stable stock of appliances - thus, an issue which will be implicitly explored in this paper is why replacing appliances suddenly became a priority.

Table 1 also serves to show that ownership levels remained high (as was representative of UK households more generally) and were largely unchanged in that appliances were mostly purchased to substitute existing ones. Few seemed to purchase new appliances that did not replace an appliance that provided almost exactly the same service. Consequently, every household owned a cooker, television and appliances with refrigeration and freezing capabilities. In addition, even fewer got rid of appliances without introducing a replacement to their home. For example, the proportion of households owning at least one specific appliance type only fell for tumble dryers, microwave ovens and dishwashers, and this mainly because of spatial constraints (which we 
Table 1 Appliance ownership changes: comparing households' pre-move-in to post-move-in stock of key domestic appliances

\begin{tabular}{|c|c|c|c|c|c|}
\hline \multirow[t]{2}{*}{ Appliance } & \multicolumn{3}{|c|}{ Ownership ( $\%$ of households with $\geq 1$ appliance) } & \multicolumn{2}{|c|}{$\begin{array}{l}\text { Replaced post-move-in } \\
\text { (\% of total households) }\end{array}$} \\
\hline & $\begin{array}{l}2 \text { month pre-move-in } \\
\text { (May 2011) }\end{array}$ & $\begin{array}{l}16 \text { month post-move-in } \\
\text { (Sept. 2012) }\end{array}$ & $\begin{array}{l}\text { UK household mean } \\
\text { average }(2010)^{\mathrm{a}}\end{array}$ & $\begin{array}{l}\text { With new } \\
\text { equivalent }\end{array}$ & $\begin{array}{l}\text { With second-hand } \\
\text { equivalent }\end{array}$ \\
\hline Cooker & $100^{\mathrm{b}}$ & 100 & - & 50 & 29 \\
\hline Washing machine/washer-dryer & 100 & 93 & 96 & 43 & 7 \\
\hline Tumble dryer/washer-dryer & 71 & 50 & 57 & 21 & 0 \\
\hline Refrigerator/fridge-freezer & 100 & 100 & - & 43 & 7 \\
\hline Freezer/fridge-freezer & 100 & 100 & - & 36 & 7 \\
\hline Dishwasher & 21 & 7 & 40 & 0 & 0 \\
\hline Microwave oven & 93 & 86 & 92 & 36 & 7 \\
\hline Laptop/desktop computer/tablet & 86 & 86 & 77 & 29 & 0 \\
\hline Television & 100 & 100 & 97 & 29 & 7 \\
\hline Mean average: & 85 & 79 & 77 & 32 & 7 \\
\hline
\end{tabular}

${ }^{\text {a }}$ Source: DECC (2013) Ownership mean percentages are based on 2010 surveys.

${ }^{\mathrm{b}}$ This total includes gas cookers (oven and hobs) as well as electrical equivalents.

discuss in detail in 'Spaces: constraining and enabling practices'). Furthermore, the only other appliance type to fall in ownership was the washing machine but that was for only one household and, even then, they opted to regularly use their parents' washing machine instead. Therefore, these appliance audits clearly suggest that appliances are a non-negotiable component of everyday domestic living - as is indeed clear from practice theory's positioning of materiality - and this is a key foundation that the rest of this study builds upon. Indeed, it is perhaps unsurprising then that multiple appliance ownership was very common for certain devices with, for instance, most households owning a second laptop/computer/tablet, and many owning three or more.

Qualitative methods: exploring why these appliance ownership changes occurred

The appliance audits that provided the background context on the previous section were also used as a basis for the semi-structured interviews that more deeply explored the influences underlying the appliance ownership changes. A (2 months) pre-move-in interview accompanied the first appliance audit, providing an opportunity to immediately discuss how and why appliances were owned and used in certain ways in their previous technological surroundings. The second appliance audit was undertaken in the weeks before discussing it in the final interview (16 months post-move-in). Additional context was gleaned from informal discussions, participant observation (e.g. resident information evenings) and a further, third, round of (walkthrough) interviews which took place in between the other two rounds at around 11 months post-move-in (March-June 2012). These additional methods were undertaken as part of wider research on this case study, and whilst it had little explicit discussion of appliance ownership, it did help provide the foundations for interview discussions and later analysis.

All these activities involved speaking to 28 individuals. Quotations in this paper are referenced using ' $1 \mathrm{~A}$ ', whereby ' 1 ' represents the individual and ' $A$ ' represents the method $(\mathrm{A}=$ pre-move-in interview with first appliance audit reflections; $\mathrm{B}=$ interim walkthrough interview; $\mathrm{C}=$ final interview and second appliance audit reflections; $\mathrm{D}=$ participant observation and informal discussions).

\section{Findings}

Complementary and conflicting technological configurations

What makes an appliance complementary or conflicting to other technologies is how technologies come together 
to form a technological configuration that services the requirements of a specific practice. This section discusses this more generally, as part of providing greater context for the following sections that together draw attention to four specific sets of influences - each of which inherently depend on the relationships between appliances and other technologies, in the context of practices.

Table 2, which was produced using data from the household interviews, presents ten examples of how appliance ownership was found to be influenced by a different domestic technological configuration (e.g. the new dwelling's technologies). These ten examples emphasise how observed changes in appliance ownership relate to other (mainly new) domestic technologies and, in particular, how that relationship is strongly influenced by a practice's images and meanings: the social expectations of how to perform a practice will impact how the relationship between appliances and other surrounding technologies is managed.

Table 2 implicitly highlights the important role that structural, building-level technologies play in shaping appliance ownership (e.g. MVHR and heating system design; gas supply). Only two of the ten examples in Table 2 involved examining the relationship between appliances and other smaller-scale technologies that the households were themselves responsible for bringing into their homes (e.g. sound-sound systems and televisions; mugs and eco-kettles).

Linked to this - as a matter of building design, rather than household purchasing and preferenceis the issue of plug socket provision, which was commonly raised during the household interviews. Indeed, domestic (appliance-using) practices have become increasingly dependent on plug sockets. It is thus perhaps expected then that the provision of plug sockets was an institutional expectation for this new build development, with the housing association stipulating the number of plug sockets (on a per room basis) in the original brief. Each onebedroom flat had 30 plug sockets, and the twobedroom and three-bedroom houses had 40 and 44 plug sockets, respectively (excluding fused spurs). This is consistent with English households' mean appliance ownership being 41 (Owen 2012), as well as a rising trend of plug socket provision: the number of plug sockets in a new build threebedroom house, as recommended by the UK
National House Building Council, has risen from 17 plugs in 1977, to 21 in 2000 and 38 in 2007 (CDA 2000; Lane 2007).

It therefore unsurprising that surveys indicate that a lack of plug sockets can be a real cause of resident dissatisfaction (CDA 2000) because they have the potential to prevent practices being performed in the ways that households wish. Indeed, we have found that appliance ownership changes have tended to come about through households attempting to enable a preferred, and very often sustain an existing, way of performing a practice (as per Table 2). In considering this, one is then drawn towards why households would want to perform practices in certain ways, leading onto a practice's associated social meanings and expectations. For example, the practices of homemaking and hosting guests seemingly demanded an expected level of thermal comfort and humidity, so as to provide a welcoming and 'homely' environment. This subsequently led to certain appliances being bought (e.g. cooling fans for summer cooling, especially when broken windows would not open) or thrown away (e.g. de-humidifiers, as the MVHR successfully maintained air quality). Furthermore, the need to align with societal expectations of stylishness and cleanliness influenced how and which appliances were used in laundering. For instance, many were unwilling for clothes (e.g. for work and socialising) to dry slowly, so the rapid and convenient drying offered by tumble dryers was a priority for them. However for those in less of a rush, but still unwilling for clothes to dry naturally more slowly, their solar gain spaces (by the large south-facing windows) were used instead of purchasing a tumble dryer.

In considering how practices shape appliance ownership, Table 2 therefore largely focuses on meanings, aspirations, ideas, attachments and motivations (the meanings element of practice). However, skills, knowledges and competences are also understood as a key influencing element of social practice (as discussed in 'Theoretical context'). It is thus worth briefly reflecting on this here with regard to appliance ownership changes. There were a few one-off examples of appliances being bought because the household did not understand how to use the Passivhaus technologies. For example, those who really struggled to understand how the external blinds, windows, MVHR, remote thermostat and heated towel rail could help keep the house cool in the summer usually owned a cooling fan. However 
Table 2 Illustrations of the interconnectedness, through practices, between the wider domestic technological configuration and domestic appliances

\begin{tabular}{|c|c|c|c|}
\hline \multirow{2}{*}{$\begin{array}{l}\text { Wider domestic technological } \\
\text { configuration }\end{array}$} & \multirow{2}{*}{$\begin{array}{l}\text { Observed change in domestic } \\
\text { appliance ownership }\end{array}$} & \multicolumn{2}{|c|}{ Relating practices to appliance ownership changes } \\
\hline & & $\begin{array}{l}\text { Predominant appliance- } \\
\text { using domestic practice(s) }\end{array}$ & $\begin{array}{l}\text { Relevant meanings of that } \\
\text { practice }\end{array}$ \\
\hline $\begin{array}{l}\text { Lounge window fitted with the } \\
\text { wrong hinges, thus could not be } \\
\text { opened }\end{array}$ & $\begin{array}{l}\text { Cooling fan bought for the lounge } \\
\text { during summer months }\end{array}$ & $\begin{array}{l}\text { Hosting, homemaking, } \\
\text { ventilating }\end{array}$ & $\begin{array}{l}\text { Being welcoming, healthy, able to } \\
\text { relax }\end{array}$ \\
\hline $\begin{array}{l}\text { No radiators (excluding a heated } \\
\text { bathroom towel rail) }\end{array}$ & $\begin{array}{l}\text { Some who previously dried laundry } \\
\text { on radiators bought tumble dryers }\end{array}$ & $\begin{array}{l}\text { Laundering, working, } \\
\text { socialising }\end{array}$ & Being clean, stylish, convenient \\
\hline $\begin{array}{l}\text { Large south-facing windows } \\
\text { providing heat through solar gain }\end{array}$ & $\begin{array}{l}\text { Good space for drying clothes } \\
\text { quickly, which led to disposing of } \\
\text { their tumble dryer }\end{array}$ & $\begin{array}{l}\text { Laundering, working, } \\
\text { socialising }\end{array}$ & Being clean, stylish \\
\hline $\begin{array}{l}\text { No external outlet for a (non- } \\
\text { condensing) tumble dryer due to } \\
\text { airtightness }\end{array}$ & $\begin{array}{l}\text { Condensing tumble dryers were } \\
\text { bought to replace non-condensing } \\
\text { equivalents }\end{array}$ & $\begin{array}{l}\text { Laundering, working, } \\
\text { socialising }\end{array}$ & Being clean, stylish \\
\hline No kitchen gas supply & $\begin{array}{l}\text { Replace gas with electric ovens and } \\
\text { hobs }\end{array}$ & Cooking, hosting & $\begin{array}{l}\text { Being healthy, a good parent/ } \\
\text { friend, skilled, worldly, } \\
\text { welcoming }\end{array}$ \\
\hline $\begin{array}{l}\text { Gaps under internal doors to } \\
\text { facilitate air circulation by MVHR }\end{array}$ & $\begin{array}{l}\text { Less powerful hi-fi speakers } \\
\text { purchased to minimise noise } \\
\text { disruption }\end{array}$ & Homemaking, hosting & $\begin{array}{l}\text { Being polite, a good household } \\
\text { member }\end{array}$ \\
\hline $\begin{array}{l}\text { Passivhaus' need for airtightness } \\
\text { strongly discourages drilling } \\
\text { through external walls }\end{array}$ & $\begin{array}{l}\text { Appliance purchases restricted by } \\
\text { number, location and } \\
\text { specifications of plug, telephone } \\
\text { line, and aerial sockets }\end{array}$ & $\begin{array}{l}\text { Communicating, hosting, } \\
\text { homemaking }\end{array}$ & $\begin{array}{l}\text { Being modern, connected, proud } \\
\text { of one's home, stylish, wealthy }\end{array}$ \\
\hline $\begin{array}{l}\text { MVHR system enables healthy air } \\
\text { quality and humidity levels }\end{array}$ & $\begin{array}{l}\text { Disposed of the de-humidifiers, used } \\
\text { in previous dwellings to inhibit } \\
\text { damp and mould growth }\end{array}$ & Hosting, homemaking & $\begin{array}{l}\text { Being clean, healthy, a good } \\
\text { parent }\end{array}$ \\
\hline $\begin{array}{l}\text { Recently bought a surround-sound } \\
\text { system }\end{array}$ & $\begin{array}{l}\text { Bought a new television that was } \\
\text { compatible with it }\end{array}$ & Hosting, homemaking & $\begin{array}{l}\text { Being modern, stylish, proud of } \\
\text { one's home }\end{array}$ \\
\hline Size of mugs & $\begin{array}{l}\text { Eco-kettle (max. capacity, half a } \\
\text { pint) replaced with a new one so } \\
\text { that more than one cup of tea } \\
\text { could be made at the same time }\end{array}$ & Hosting & $\begin{array}{l}\text { Being polite, welcoming, time } \\
\text { efficient }\end{array}$ \\
\hline
\end{tabular}

more generally, skills, of whatever form, were very rarely a barrier to a household changing appliances. Indeed, when skills were raised in interviews, residents commonly laughed it off by commenting on how most appliances are based on similar principles which they have learnt through past experience. Therefore, whilst skills and knowledges are essential to operating appliances and hence performing appliance-using practices, they had very little influence on the household changing which appliances they owned. Whereas meanings and expectations which 'engaged' (c.f. Gram-Hanssen 2011) individuals in specific ways of performing a practice dominated ownership changes - this will continue to be apparent through the rest of this paper's findings and discussion, which largely focuses on technologies and meanings of everyday practices.

Influences associated with moving into Passivhaus homes

This section considers two key sets of Passivhausspecific influences that clearly shaped household appliance ownership around move-in. Specifically, these relate to (1) how appliances play an active role in managing thermal comfort in Passivhaus homes, and (2) how appliances could help to mitigate potential disruptions to everyday life, which linked to the unfamiliarity of emerging (e.g. Passivhaus-related) technologies. 


\section{The thermal role of appliances}

Passivhaus technologies - specifically those that provide airtightness and super insulation-significantly minimise heat loss. Heat provided by the occupant's own body warmth and, crucially for this discussion, the use of electrical appliances therefore helps heat one's home. Figure 1's rigid distinction between electricity and heating fuel is therefore blurred. Whilst the vacuum cleaner was the most commonly referred to device for generating heat, every household told stories of how almost every appliance heated the home. Indeed, often too much heat was generated with, for instance, the remote thermostat 'display[ing] at least 27 degrees when the TV is switched on' (2B). Passivhaus construction has thus imposed upon appliances the additional role of being heaters. One resident spoke of a laptop not as a communications device but as a heater for her daughter's bedroom, mainly because it remained powered on all of the time. Unsurprisingly, residents also commented on how they could 'feel a change [in temperature] when more than one [appliance] is used at any one time' (11C). Practices which encompass appliances in certain ways have hence gained new meanings (i.e. relating to temperature regulation) in addition to more established and conventional meanings (e.g. of a television providing a reference point for relaxation and hosting). The shift in emphasis was demonstrated by some residents pre-empting any concerns (they deemed we would have) regarding electricity consumption, by explaining in the interviews how usage was essential in maintaining comfortable temperatures.

The implications of this additional (thermal) role in domestic appliance-using practices were evident upon appliance ownership. However, each household was influenced in a different way because the thermal impact of an appliance depended upon how that appliance was used in performing practices. For instance, one household that watched a lot of television found their high electricity consuming plasma screen to be overheating their home frequently during summer months, whereas a household with a similarly inefficient screen who watched much less television reported no such problems. Interestingly, all members of the overheated household recalled conservations with each other about buying an LCD television which would use less electricity and thus affect temperatures less. Passivhaus technologies had for many therefore brought energy efficiency to the fore in the purchasing of appliances, not for environmental or monetary benefits, but because thermal comfort expectations had become more relevant for domestic practices.

Passivhaus buildings were rarely too cool, and, as such, over half of the households disposed of plug-in heaters around move-in. In part this was because the appliances helped to fill that heating need, but it is more related to the significantly lower heat loss rates that Passivhaus design ensured. Despite residents being told by the housing association at pre-move-in information sessions that they would not need plug-in heaters, residents only disposed of any heaters they owned after experiencing it for themselves post-occupancy. Tacit learning was shaping practices, and thus in part appliance ownership. The situation regarding ownership of electric cooling fans was slightly different in that a few households disposed of their fans before moving home, rather than in response to experience. Nevertheless, because of post-occupancy experience, all of these same households regretted disposal with each buying a new fan to alleviate the higher than expected summer indoor temperatures - specific examples included needing a cooling fan when watching television, vacuuming or cooking on warmer days.

There were some one-off examples of replacing or throwing away appliances because of their effect on temperature (e.g. replacing an old CRT television in a south-facing bedroom), but on the whole very few appliances were disposed of. Again, this relates to the fact that appliances are deeply embedded in the performance of domestic practices. In response to appliances' new thermal role, residents consciously or not typically made changes to how and when rather than what and which appliances were used. In this way, appliance-using practices only needed to be slightly adjusted to achieve the same ends within this new Passivhaus setting. Changes to the how largely centred on juggling performances of multiple practices alongside each other. Passivhaus technologies seemed to establish closer associations across domestic everyday practices because they could all influence and be influenced by thermal comfort. The consequence was that adjustments to both applianceand non-appliance-using practices were needed to accommodate for there being little flexibility in the types of appliances being used (e.g. clothing: never vacuuming with a jumper on; cooking: summer meal choices ensure the oven is used less). By extension, this also led to many households multi-tasking less during the summer (e.g. not vacuuming when cooking), which 
discussion of daily routines in the pre-move-in interviews showed to be common. Changes to the when included a temporal stretching of some practices so that the cumulative heating effect was more sparsely distributed (e.g. laundering: not using the tumble dryer immediately after washing). Therefore, if thermal comfort - or, as many residents described it, 'cosiness' $(11 \mathrm{~A} ; 19 \mathrm{~A} ; 2 \mathrm{C} ; 13 \mathrm{C} ; 14 \mathrm{C})$ - was to be maintained, other adjustments to how and when practices were performed (away from what and which appliances) had to be made.

\section{Maintaining practices and avoiding disruption: breakdown contingencies}

If appliances were to break then the practices themselves would have to change, even if it only temporarily until technologies were repaired or replaced. Fear of disruption was implicit to many resident discussions, with it clearly influencing appliance ownership.

There was safety in purchasing new appliances because of the reliability offered and, in the deemed unlikely event of a malfunction, repairs could be quickly organised through the product's warranty, and this was said to be especially important because of a general fear that the Passivhaus technologies may in themselves cause disruption. Moreover, second-hand appliances were often deemed to not provide the required reliability and thus the surety that everyday life would be protected. Interestingly, not one resident talked of insurances which could also provide protection, instead focusing on the appliances themselves, perhaps because replacement of broken old appliances was deemed a burden on everyday life regardless of who was paying. Such was the importance of reliability that one household did happily buy a second-hand refrigerator, but only because the manufacturer was regarded as reputable, and they resolutely refused 'to ever buy washing machines or hoovers [vacuums] second-hand as [family (relative 'experts') had insisted that] they probably wouldn't work' (11C).

The wider technological configuration in which the appliances sat clearly influenced notions of reliability. Many households were genuinely concerned by the unfamiliar Passivhaus technologies because they had very few relevant skills and competences that could deal with the breakdown of the MVHR and solar thermal systems. The few households that did suffer breakdowns thus kept fan heaters, despite never using them, just in case a problem with heating was to arise again. In many ways this was about the residents not placing sufficient trust in the Passivhaus technologies. Keeping certain appliances, such as a fan heater, therefore provided a safety net in case another breakdown was to occur. Such appliances were consequently kept in reserve and not used simply because they were available.

Appliances are so embedded within domestic practices that when certain appliances failed - in particular the larger items and white goods - replacement as soon as possible was seen as essential. Such breakdowns occurred for a few households when moving the appliances from their old to new home. When talking about these past breakdowns, the panic it caused was clear to see, particularly due to its timing. The frustration of having to replace appliances at an already expensive time was not ideal, but the residents talk as if they had no choice but to buy them. Domestic practices (e.g. cooking, laundering) rely on washing machines, refrigerators, cookers and the like. They were unwilling to either stop performing these practices or significantly adjust their performances to cope without an appliance, the reasons of which link back to a practice's social expectations. Since buying a replacement appliance was therefore seen as an urgent but costly need, the same few households had to (in the interim at least) source replacements from friends and family or potentially buy the cheapest second-hand equivalent available. In these instances, older energy-inefficient appliances were typically acquired which, whilst cheaper or more convenient, could be detrimental to longer-term thermal comfort (as was explored further in 'The thermal role of appliances').

Influences associated with moving home

Although this study focuses on a sample of households moving into new build Passivhaus homes, it was clear that many of the appliance ownership changes could not be solely attributed to Passivhaus. This section thereby considers two key sets of influences that are associated more generally with the processes of moving and making a home, which are also relevant beyond the Passivhaus context. Specifically, these relate to (1) how the spatial layout of a new home impacts upon what can be brought into it, and (2) how the expectations 
attached to a 'new' home also led to the purchase of 'new' appliances.

\section{Spaces: constraining and enabling practices}

Technological design and layout can both impose spatial constraints and provide opportunities for conducting certain practices in certain ways. Although this subsection is largely couched in the context of dwelling space and how appliances fit within that, consideration is also given to the capacity of appliances (e.g. refrigerator/ freezers being large enough).

During most resident discussions, if there was one issue that would spark a passionate response, it was space. However, whilst the most important issue for many, space was rather a non-issue for others. Whether a dwelling provides adequate space very much depends upon the practices being undertaken within it. It is exactly for this reason that one resident explained how initial worries of downsizing from a three-bedroom to a one-bedroom dwelling were unwarranted because everyday life had changed her space demands, now she was living on her own.

Looking at one particular element of space-specifically, the capacity of certain appliances-further demonstrates how practices are shaping appliance ownership. One household that grew by one adult halfway through the study considered buying a larger fridge-freezer as essential because of the change in household practices that the larger fridge-freezer was capable of facilitating. For example, a larger fridge-freezer allowed for more storage as more food needed to be cooked and the likelihood of guests visiting for dinner increased. The foundations of such deliberations can be found in how cooking practices have developed over time, to the point where they considerably rely on cold appliances for food storage. Otherwise, a smaller fridgefreezer or indeed no fridge-freezer could have been adequate.

Shove and Southerton (2000) also explore space in terms of cold appliances, discussing how practices and arrangements associated with the development of supermarkets, frozen food, the microwave and kitchen design approaches have normalised freezer ownership. Indeed, every household in this study owned a freezer (Table 1), which is perhaps unsurprising considering how cold chain technology 'has made itself indispensable' (Garnett 2007, p. 5) in everyday life. Moreover, Shove and Southerton (2000, p. 315) argue that the freezer can currently be seen as a 'time machine', in that it helps 'manage the otherwise intolerable demands of scheduling, ordering and co-ordination'. Most households were keen to utilise the time-efficient shortcuts that greater freezer capacity provides:

I'm one of those people that can always fill the freezer up! I could always do with more space! It just speeds up cooking meals. Plus, I can store more, so don't have to shop as much. But this [freezer capacity] is adequate, I suppose.

(25C)

Many households would have preferred scope for more or larger freezers, often only being limited by spatial restrictions set by the kitchen design. One such household talked of how they considered buying a chest freezer, but had thought it an inefficient use of space because it uses too much floor space for the amount of freezer capacity it provides. Since juggling the need for adequate freezer capacity within the dwelling's own spatial constraints posed such a challenge, most households owned a fridge-freezer due to its efficient use of space-also meaning that households did not have to choose between having a refrigerator or freezer.

The space created by dwelling design can make households re-negotiate previously non-negotiable ways of performing a practice. In reference to moving to a dwelling with different (often smaller) spaces, residents commonly spoke of how it made them 'more ruthless in throwing things [appliances] out' (9C). Whilst moving home was associated with meanings and expectations of what a new home is meant to entail (as 'New appliances for a new home: keeping up appearances' furthers), there was evidence to suggest that the moving of possessions to a new dwelling (with its associated spatial characteristics) contributed to a prioritisation of appliances. This was particularly salient regarding fitted kitchens which imposed certain spaces upon the household to fill with kitchen appliances. In the most basic sense, the limited space led households to prioritise appliances (e.g. not having a dishwasher) and by extension certain ways of performing a practice (e.g. washing up dirty dishes instead). For instance, the cooker, refrigerator, freezer (central to cooking) and washing machine (laundering) technologies were given prime locations. When discussing this in interviews, it became 
apparent that these prioritisations were being shaped by the social expectations of not only performing certain domestic practices (e.g. cooking, laundering), but performing them in rather specific ways (e.g. with specific appliances).

Some appliances that were previously in prime positions could now only be accommodated in less preferable 'empty spaces' (1C) 'because there was nowhere else to put them' (4B). This spillover into non-ideal spaces provided a buffer for appliance ownership, helping the continuation of a practice in as near to its previous form as possible. We would infer that years of reperforming the same practice with the same appliances had reinforced that construction of everyday life, making it difficult for households to imagine life without those appliances. This meant that some households would do whatever they could - sometimes consciously, sometimes not - to not throw away appliances that had been regularly used previously. Interestingly, those same households began to normalise their new technological interactions as time went by, emphasising that lowering appliance ownership is likely to be met with household disapproval potentially only in the shortterm:

I did move the tumble dryer to my bedroom, but it hasn't been used all the time I've been here. I could run a lead through, but I'm not too happy about that idea! My clothes dry just as well on a clothes-horse in the plant room. It is handy having the dryer, but I don't feel there is all that much space for it, so it's ended up in the shed, just in case I need it at some point in the future.

(3C)

Whilst most spoke very positively about having no radiators which had previously restricted how objects were organised in a room, those residents who relied on radiators for energy services beyond that of simply keeping warm spoke about it much more negatively. For example, laundering in one household had always relied on the radiators for drying clothes quickly, which was essential for work purposes and a young child who was 'always getting dirty' (27D). Not having adequate space for a tumble dryer in addition to, as they saw it, no suitable place for drying clothes only compounded this problem further. They bought a (high electricityconsuming) washer-dryer so that changes to their laundering practice (e.g. using a washer-dryer) would not change their clothing practices (e.g. still did not have to wear clothes more than once before laundering, as dictated by social notions of cleanliness). A lower electricity-consuming alternative to maintaining their current clothing practices could be the provision of a designated clothes drying area (e.g. a small cupboard connected to the MVHR), as has been purposively designed into other Passivhaus developments.

Marked spatial differences, relative to one's previous home, can also create opportunities for performing existing practices, or even establishing new practices, in previously sought after ways. This was largely only the case for a few households who had previously been living in much smaller dwellings. As one resident explained, 'with having more space, sometimes I see things that I've always wanted, and now I've got room to put it' (25C). One household had always dreamed of having an outdoor hot tub to host friends and relax in during the summer, but they had not had a garden for the previous 10 years. They still talk of even having that possibility very fondly and, needless to say, within a month of moving in they bought a hot tub saying to one another, 'well, we've got a garden now, this will be great!' (26C). Spatial constraints, as determined by their technological surroundings, was therefore the key inhibitor stopping them from purchasing this (high electricity-consuming) appliance. These sorts of tales were not uncommon, contributing to a shared 'if you've got the space, fill it' mentality.

\section{New appliances for a new home: keeping up appearances}

Moving home in itself involved the re-evaluation of appliances, with a few households hiring a skip for disposal of various items prior to moving. For some this was simply because there was no 'point [in] moving things to a new house that I won't use again' (12C), but for most, moving home represented a 'good time to start afresh' (14C). It is what this fresh start means to households that this subsection explores, in relation to what appliances were deemed suitable. The situation is complex, going far beyond issues of functionality; otherwise, why would many households have each bought a new microwave with an almost identical specification (e.g. wattage) to replace older microwaves which, according to the households, were still in working order?

For many, new appliances were essential for a new home, particularly as their new homes were new build 
properties. There was a need for 'more modern items for such a nice, new house' (13C). It was very common to delay purchasing new appliances ('making it last' $(25 \mathrm{C})$ ) in the lead up to moving home, so that the enjoyment of having something new could be reaped, and presumably enhanced, by their 'lovely new home' (8C). Discussions with the residents indicated that the meanings and expectations of performing practices with these newer appliances were to convey social status, wealth, the ability to provide for one's family, modernity, stylishness, and that the new home was not regarded as out of one's reach. This was particularly evident for hosting and homemaking practices. Consequently, when reviewing the market for appliances for their fresh start, second-hand items were not considered appropriate by most households:

It didn't even occur to us to get second-hand [appliances] for this house [despite always doing so previously]. You've got a new house, a new kitchen, and you just want it all new!

(24C)

You don't want to fill your new house with rubbish [i.e. second-hand appliances]. You want to start as you mean to go on, so only good stuff [i.e. new appliances].

Aesthetics were intrinsic to these meanings surrounding 'keeping up appearances'. Having appliances which matched each other and the general decor was commonly discussed across most interviews; thus, in many cases, non-matching appliances either had been or were planning to be disposed of. One resident spoke proudly of how her recently bought kitchen items had been carefully co-ordinated:

Have you seen that all my red things match? They are all the same make. The microwave, the [storage] pots, the kettle, the toaster. They have to match! We didn't have them when we moved in here. Once we bought one, we had to buy all the others so they were co-ordinated!

Another household talked of how future purchases of brand new matching appliances had already been planned out for first few years of living in the property.
Their older appliances from their previous home were being treated as a stop-gap prior to buying the ones they really wanted. Savings schedules had effectively been drawn up to replace old appliances with equivalents that better suited the image of a new home, and thus the meanings of the practice of homemaking. It is worth noting here that this was actually the only context in which money was raised when discussing appliance purchases during the interviews - i.e. how costs could delay a purchase, en route to them performing a practice in a desired way-with seemingly no consideration given to energy running costs by any of the households.

When questioned more generally about kitchen layout and appliances, several residents independently raised the issue of gaps in between appliances and the fitted kitchen's work surfaces. It was usually raised to either criticise neighbours who had gaps or, in one case, to pre-empt any concerns others may have about their own gaps. This was in part aesthetic, but seemed largely rooted in conventions of cleanliness in that gaps would attract dirt, dust and food waste which could not be easily accessed and removed. This conflicted with the homely conditions that a good host or homemaker were expected to provide. Some residents therefore criticised other residents' general competence in buying kitchen appliances because they did not understand the importance of dimensions when ordering. Indeed, one resident critically remarked, 'our cooker fits in perfect [sic], but Susan's over there, she didn't check her measurements before she ordered her oven, so she has gaps!' (21C). Another resident was disappointed that 'it never occurred to me I would need a washing machine that would fit exactly' (10C). Social expectations of how to interact with the material world (e.g. a fitted kitchen), as determined by hosting and homemaking practices, therefore influences the specification of purchased appliances (e.g. size, thus usually also electricity consumption).

The practices of every shared owner were to some extent influenced by these social expectations of how best to create, maintain and present their new home. Whilst some tenants were similarly influenced, some explicitly discussed how they were not worried about making the 'perfect home'. In general, the shared owners seemed to have more of an attachment and sense of pride relating to their dwelling. This may in part be influenced by investing money and time into purchasing (part of) the dwelling, but the purchase also represented a commitment to living in their new 
home for longer. The shared owner households hence aspired to future visions of living in their new home for years to come, which consequently influenced appliance choice. This was made especially clear by one household who made a distinction between what appliances were suitable for her new home, as opposed to all her previous homes which had only been occupied for a few months at a time.

\section{Discussion}

This section emphasises four cross-cutting themes. First, appliances are essential to domestic practices. Certain appliances were commonly referred to as a need. This was reflected by many appliance types (e.g. cooker, television, refrigerator, freezer) being owned by every household both before and after moving home. Certain appliances were non-negotiable, and even those appliances that were not owned by every household were still usually described as essential or a need to that specific household's everyday life. Indeed, appliances were so integral to everyday life that fear of breakdown, which could disrupt the convenience or even possibility of performing a practice, strongly influenced appliance purchases (e.g. reason for replacements, not buying second-hand and/or having an alternative appliance option available).

Second, appliances are relational; thus, the wider technological configuration that the appliance(s) fits within needs consideration, specifically, how the configuration influences the practices that use it. For instance, dwelling-level materiality was shown to clearly influence the appliances that households used in appropriating their dwellings, both more generally with spatial constraints leading to prioritisation of appliances, and more specifically through Passivhaus technologies giving appliances a heating role. By giving practices the spotlight, the importance of inter-technological relationships became particularly apparent because of how practices bind technologies together in respective configurations. Practices connect and make technologies relevant.

Third, changes to appliance ownership are largely attributed to the 'meanings' (per Shove et al. 2012) of everyday practices. The expectations, aspirations and symbolic associations attached to performing domestic appliance-using practices in certain ways dominated the influences underlying appliance ownership changes. The meanings element of practice therefore played a more prominent role in shaping the materials element (including appliances), in comparisons to the competences element which relatively rarely came to the fore. Whilst skills are needed to be able to perform a practice, they were only a small influence in changing appliance ownership. More generally, the dominance of meanings was illustrated by numerous examples in Table 2 .

Moreover, the desire to keep up appearances (e.g. coordinated, clutter-free, modern) in the households' hosting and homemaking practices further emphasises the significant influence of the images and expectations of practice. Even though spatial constraints and contingency planning may seem to have been the initial stimulus for some appliance ownership changes, these only occurred so as to serve certain performances of practices which upholds certain associated meanings. For instance, and more specifically related to the case studied, appliances also being heating devices led to new associations between appliances and thermal comfort social expectations (e.g. in turn leading to greater consideration of energy-efficient appliances that generate less heat). Whilst there is no single linear solution to transform appliance-using practices and thus appliance ownership, targeting the social significance and symbolic meanings associated with appliances-using practices in new homes would certainly aid the transition.

Fourth, variety in the individual performances of practices led to each household owning different appliances. Throughout this paper, we have emphasised the embeddedness, stability and non-negotiability of practices and the technologies that utilise them. Indeed, a social practice is usually performed through roughly similar means to achieve roughly similar ends. In actuality, this, only rough, similarity means differences exist in how the same social practices are individually performed. These performance differences can contribute to different (perhaps unanticipated) appliances becoming firmly embedded in an individual household's everyday practices. Unintended consequences are a common product of practices and part of what makes them so very difficult to govern.

These four themes implicitly reinforce the conclusions of Shove et al. (2007, p. 141), regarding their research on the practical usage of everyday objects, who emphasise that 'things are acquired, discarded and re-designed with reference to culturally specific expectations of doing and of having - not of having alone'. As they simply put it, 'doing matters for having and having matters for doing' (Shove et al. 2007, p. 
142). Therefore in researching technological ownership (having) - in this case, of appliances - one is unable to separate it from the performance of practices (doing).

\section{Conclusions}

This paper aims to investigate how moving home can influence appliance-using practices and thereby appliance ownership levels. A clear strength of this study is its methodological approach because it, unlike many similar studies, both audited the appliances and interviewed the households before as well as after move-in. A Passivhaus development was used as a case study, as part of highlighting potential ownership changes that could occur as housing stocks improve their energy efficiency in the future. The electricity consumed by these households in their previous dwellings was very similar to the amount consumed in their new Passivhaus dwelling. Yet despite this, significant changes in appliance ownership were evident for every household, both with regard to the total number and individual specifications of each appliance type.

Changes in appliance ownership were caused by changes in how appliance-using practices were being performed and, in particular, how these practices responded to the new surroundings that the households were attempting to call home. Some of these influences were largely specific to the Passivhaus context, such as appliances impacting thermal comfort, and the expectation that Passivhaus technologies could go wrong and thereby disrupt everyday life. Whereas other influences were more relevant to moving home more generally, such as the expectation that new appliances best complement a new home, and that the spatial layout of a building will shape what appliances can brought into it.

This paper has reiterated how the elements of appliance-using practices can change when moving home. Whilst this is perhaps most obvious with regard to materiality (e.g. a new physical house that one can call home), it was actually the relationship between material changes and changes to the meanings of appliance-using practices that was most important in driving changes to appliance ownership. In contrast, the competences of appliance-using practices did not inhibit the purchase or disposal of appliances, with it assumed by households that they had (or would relatively easily be able to acquire) the relevant knowledges to operate newly purchased appliances in their new home. Therefore, the images and social expectations of how households perform practices in a new home were critical, and this was not only for the practice of homemaking itself but also for almost every domestic practice (as these were now being performed at a new 'site'). Indeed, a new home led to the enhancement of many of the meanings of cooking, laundering, hosting and thermal comfort practices (e.g. more stylish, modern, convenient, clean), which tended to also make the practices more unsustainable.

As Passivhaus is a building standard, this case study also provides insight on how the standardisation of buildings could impact appliance-using practices, or indeed practices more generally. Admittedly, the Passivhaus standard does not prescribe a particular construction approach, but it does nevertheless (through the targets it sets) pull buildings in a common direction (e.g. airtightness, super insulation), and it is this direction that has directly influenced appliance ownership (e.g. through appliances now also being heaters). Similarly, but aside from Passivhaus, the default floor area standards for what was deemed as a 'normal' size for threeor four-bedroom houses posed spatial constraints, which inhibited certain performances of practice and hence the ownership of certain types of appliances too. Broader consideration is thus needed of how standards that focus on building structure and form could begin to standardise how people live. However, there are also many unspoken 'standards' (e.g. number of plug sockets) that are institutionally engrained in design and construction practices, and these more informal standards also require our attention. Indeed how many plug sockets, for instance, will our homes have in 2050 and what implications could that have for our energy reduction targets? Which specific design strategies are more likely to lead households to certain modes of everyday living? How does the sizing of appliances relate to the default size assumption of building design? How is what is 'normal' design and construction shaping what is 'normal' everyday living for households? And should we even be attempting to 'standardise' building design in certain (more preferable) ways? Such questions are of vital importance as we consider how our next generation of buildings are constructed.

Acknowledgments Many thanks to Charlie Wilson and the two anonymous reviewers for their helpful comments on earlier versions of this paper, and also to the Economic and Social Research Council for funding the primary researcher (Grant number: ES/ H011129/1). 
Open Access This article is distributed under the terms of the Creative Commons Attribution 4.0 International License (http:// creativecommons.org/licenses/by/4.0/), which permits unrestricted use, distribution, and reproduction in any medium, provided you give appropriate credit to the original author(s) and the source, provide a link to the Creative Commons license, and indicate if changes were made.

\section{References}

Bourdieu, P. (1984). Distinction: a social critique of the judgement of taste. London: Routledge.

CDA. (2000). Electrical convenience in New build homes survey report. Hemel: Hempstead. Available: http://www. copperinfo.co.uk/residential/downloads/pub-140-electricalconvenience-new-build-for-builders.pdf.

DECC. (2013). Energy consumption in UK-chapter 1: overall data tables (2013 update). London: Department of Energy and Climate Change. Available: https://www.gov.uk/ government/publications/energy-consumption-in-the-uk.

Efstathiou, A., Grant, D., \& Maxwell, S. M. (2004). The ownership and use of small kitchen domestic appliances: case study, Liverpool. International Journal of Consumer Studies, 28(3), 305-311.

Energy Saving Trust. (2011). The elephant in the living room: how our appliances and gadgets are trampling the green dream. London: EST. Available: http://www.ncbi.nlm.nih.gov/ pubmed/21164213.

Feist, W., Schnieders, J., Dorer, V., \& Haas, A. (2005). Reinventing air heating: convenient and comfortable within the frame of the passive house concept. Energy and Buildings, 37(11), 1186-1203.

Garnett, T. (2007). Food refrigeration: what is the contribution to greenhouse gas emissions and how might emissions be reduced? (Food climate research network working paper series). Guildford: Centre for Environmental Strategy, University of Surrey.

Giddens, A. (1984). The constitution of society: outline of the theory of structuration. Cambridge: The Polity Press.

Gram-Hanssen, K. (2010). Standby consumption in households analyzed with a practice theory approach. Journal of Industrial Ecology, 14(1), 150-165.

Gram-Hanssen, K. (2011). Understanding change and continuity in residential energy consumption. Journal of Consumer Culture, 11(1), 61-78.

Gram-Hanssen, K. (2013). Efficient technologies or user behaviour, which is the more important when reducing households' energy consumption? Energy Efficiency, 6(3), 447-457.

Hand, M., \& Shove, E. (2004). Orchestrating concepts: kitchen dynamics and regime change in good housekeeping and ideal home, 1922-2002. Home Cultures, 1(3), 1-22.

Hand, M., \& Shove, E. (2007). Condensing practices: ways of living with a freezer. Journal of Consumer Culture, 7(1), 79-104.

Hargreaves, T. (2011). Practice-ing behaviour change: applying social practice theory to pro-environmental behaviour change. Journal of Consumer Culture, 11(1), 79-99.

Lane, M. (2007). A solution to the socket shortage? London: British Broadcasting Corporation. Available: http://news. bbc.co.uk/1/hi/magazine/6705313.stm.
Leahy, E., \& Lyons, S. (2010). Energy use and appliance ownership in Ireland. Energy Policy, 38(8), 4265-4279.

Mansouri, I., Newborough, M., \& Probert, D. (1996). Energy consumption in UK households: impact of domestic electrical appliances. Applied Energy, 54(3), 211-285.

McLeod, R. S., Hopfe, C. J., \& Rezgui, Y. (2012). An investigation into recent proposals for a revised definition of zero carbon homes in the UK. Energy Policy, 46, 25-35.

McMeekin, A., \& Southerton, D. (2012). Sustainability transitions and final consumption: practices and socio-technical systems. Technology Analysis \& Strategic Management, 24(4), 345-361.

Monahan, J., \& Powell, J. C. (2011). A comparison of the energy and carbon implications of new systems of energy provision in new build housing in the UK. Energy Policy, 39(1), 290-298.

O’Doherty, J., Lyons, S., \& Tol, R. S. J. (2008). Energy-using appliances and energy-saving features: determinants of ownership in Ireland. Applied Energy, 85(7), 650-662.

Owen, P. (2007). The ampere strikes back: how consumer electronics are taking over the world. London: Energy Saving Trust.

Owen, P. (2012). Powering the nation: household electricity-using habits revealed. London: Energy Saving Trust and the Department of Energy and Climate Change, and Department for Environment, Food and Rural Affairs.

Reckwitz, A. (2002). Toward a theory of social practices: a development in culturalist theorizing. European Journal of Social Theory, 5(2), 243-263.

Røpke, I. (2009). Theories of practice-new inspiration for ecological economic studies on consumption. Ecological Economics, 68(10), 2490-2497.

Sandberg, J., \& Haridimos, T. (2011). Grasping the logic of practice: theorizing through practical rationality. Academy of Management Review, 36(2), 338-360.

Schatzki, T. R. (2002). The site of the social: a philosophical account of the constitution of social life and change (first.). Pennsylvania: Pennsylvania State University Press.

Schatzki, T. R. (2011). Where the action is (on large social phenomena such as sociotechnical regimes). Manchester: Sustainable Practices Research Group Working Paper 1.

Schatzki, T. R., Knorr Cetina, K., \& Von Savigny, E. (2001). The practice turn in contemporary theory. The practice turn in contemporary theory. London and New York: Routledge.

Shove, E. (2010). Beyond the ABC: climate change policy and theories of social change. Environment and Planning A, 42(6), 1273-1285.

Shove, E., \& Hand, M. (2000). The restless kitchen: possession, performance and renewal (Kitchens and bathrooms: changing technologies, practices and social organisation-implications for sustainability, interdiscilinary workshop (pp. 1-15)). UK: University of Manchester. 27-28 January.

Shove, E., \& Southerton, D. (2000). Defrosting the freezer: from novelty to convenience: a narrative of normalization. Journal of Material Culture, 5(3), 301-319.

Shove, E., Watson, M., Hand, M., \& Ingram, J. (2007). The design of everyday life. Oxford and New York: Berg.

Shove, E., Pantzar, M., \& Watson, M. (2012). The dynamics of social practice: everyday life and how it changes. London: Sage Publications.

Southerton, D. (2001). Consuming kitchens: taste, context and identity formation. Journal of Consumer Culture, 1(2), 179-203.

Thompson, S., Michaelson, J., Abdallah, S., Johnson, V., Morris, D., Riley, K., et al. (2011). "Moments of change" as opportunities 
for influencing behaviour: a report to the Department for Environment. London: Food and Rural Affairs. Available: http://randd.defra.gov.uk/Default.aspx?Menu= Menu\&Module $=$ More $\&$ Location $=$ None $\&$ Completed $=$ $0 \&$ ProjectID $=16193$.

Verplanken, B., Walker, I., Davis, A., \& Jurasek, M. (2008). Context change and travel mode choice: combining the habit discontinuity and self-activation hypotheses. Journal of Environmental Psychology, 28(2), $121-127$.

Warde, A. (2005). Consumption and theories of practice. Journal of Consumer Culture, 5(2), 131-153.
Wilhite, H. (2012). Towards a better accounting of the roles of body, things and habits in consumption. In A. Warde \& D. Southerton (Eds.), The habits of consumption (pp. 87-99). Helsinki: COLLeGIUM of Studies Across Disciplines in the Humanities and Social Sciences.

Zimmermann, J.-P., Evans, M., Griggs, J., King, N., Harding, L., Roberts, P., et al. (2012). Household electricity survey: a study of domestic electrical product usage. Produced on behalf of the Energy Saving Trust, Department of Energy and Climate Change, and Department for Environment, Food, and Rural Affairs, by AEA Technology, Intertek, Ipsos MORI and Enertech. London. 